\title{
«Que también sé yo hacer bailes»: Lope de Vega y el baile dramático
}

\author{
«Que también sé yo hacer bailes»: \\ Lope de Vega and the dramatic dance
}

Francisco Sáez Raposo

Universidad Complutense de Madrid

RESUMEN: En el presente trabajo analizaré el peso que el mito de Lope de Vega tiene a la hora de adjudicarle la autoría de algunas piezas breves, pues se exigen para ello unas garantías totalmente legítimas desde el punto de vista científico, aunque tal vez un tanto radicales desde el de la sensatez filológica. Además, defenderé su concurso en uno de los subgéneros que más se le han negado: el baile dramático. Para ello, intentaré aportar pruebas que demuestren que el Fénix no sólo estuvo interesado en este tipo de creaciones, sino que, de hecho, compuso alguna que se puso en escena en fiestas palaciegas a comienzos de la década de 1630.

Palabras clave: Lope de Vega, teatro, baile dramático, entremés, teatro breve.

ABSTRACT: This paper analyzes the significance and consequences of Lope de Vega's status as a legend when it comes to accepting his authorship of a few short plays, given that critics tend to demand extra proof in this matter, sometimes going beyond reasonable philological demands. I will also defend the idea that Lope was an author of dramatic dances, one of the subgenres which critics have always been reluctant to link with his name. To this end, I will cite evidence to prove that 'el Fénix' not only felt an interest in these sort of plays but also composed some which were staged in courtly performances in the early 1630 s.

Keywords: Lope de Vega, drama, dramatic dance, dramatic interlude, short drama. 
Lope de Vega y teatro breve son dos valores de una ecuación que no termina de resolver su incógnita. En un campo tan abonado para la adjudicación de autorías como es el género entremesil, la sombra del Fénix deja sentir su presencia cada cierto tiempo. El empeño y la aspiración cíclicos por asentar al icono de nuestro teatro áureo en el último territorio dramático que se le resiste inducen a embarcarse en un peligroso viaje hacia un destino incierto (o inexistente) en el que la única seguridad con la que se cuenta al soltar amarras es la de tener viento de proa para navegar a través de aguas procelosas. Sin embargo, parece difícil de aceptar que hoy, cuando el teatro breve hace tiempo que se liberó del peyorativo marbete de «menor» y los estudios al respecto han resucitado aquel aplauso que se apagó en el proceso de transferencia de las tablas al papel, Lope siga manteniéndose prácticamente ajeno a él. Se diría que casos como el de Calderón han estimulado el interés por hallar la prueba que le sitúe de una vez por todas y de manera irrefutable en la órbita de este género. La faceta de entremesista de aquel, redescubierta en la década de $1980^{1}$, no sólo ha ido acrecentando su consideración crítica, sino que ha permitido abrir nuevas vías de interpretación del conjunto de su producción dramática a través del filtro del humor, conformando una visión poliédrica de su figura, mucho más compleja, alejada de esa imagen de gravedad y circunspección, de quintaesencia del Barroco y, en especial, de uno de sus géneros dramáticos más inconfundibles: el auto sacramental.

Aunque Lope no está solo en esta especie de rebeldía creativa (le acompaña Tirso), su caso es especialmente punzante al tratarse del catalizador y abanderado de la revolución escénica que tuvo lugar entre finales del siglo XVI y principios del XVII. Su hiperbólica personalidad, su compulsivo impulso creativo, su apego por lo popular así como su obsesivo afán por señalarse entre los más ilustres ingenios en todas las disciplinas literarias plantean una duda razonable sobre su hipotética incursión en el universo teatral breve. A diferencia del mercedario, al que las piezas que se le atribuyen no llegan a una decena ${ }^{2}$, la nómina de composiciones que en algún momento se han vinculado a Lope no es nada desdeñable. En el artículo que en su momento preparé sobre su producción dramática breve para el Diccionario filológico de Literatura Española dirigido por Pablo Jauralde ${ }^{3}$, recopilé noticias de casi un centenar de composicio-

\footnotetext{
${ }^{1}$ Fueron pioneros los trabajos de Evangelina Rodríguez Cuadros y Antoni Tordera (Calderón y la obra corta dramática del siglo XVII, London, Tamesis, 1983 y Pedro Calderón de la Barca. Entremeses, jácaras y mojigangas, Madrid, Castalia, 1990) y María Luisa Lobato (Pedro Calderón de la Barca. Teatro cómico breve, Kassel, Reichenberger, 1989).

${ }^{2}$ Todas ellas aparecieron incluidas en la Segunda parte de las comedias del maestro Tirso de Molina que se publicó en Madrid en 1635.

${ }^{3}$ Francisco Sáez Raposo, «Félix Lope de Vega Carpio. Teatro menor», en P. Jauralde Pou, dir., Diccionario filológico de literatura española (Siglo XVII), Madrid, Castalia, 2010, vol. I, págs. 863-886.
} 
nes de atribución más o menos dudosa, incluida una loa hoy perdida ${ }^{4}$, que abarcarían a toda la familia entremesil. Ello sin mencionar sus autos sacramentales, cuyo número incrementa de manera considerable dicha cantidad.

Aunque estas premisas esbozan un panorama halagüeño de cara a ubicar definitivamente a Lope en el Parnaso entremesil, los pasos que se han ido dando en este sentido han sido recibidos con escepticismo y una falta de consenso suficientes como para seguirle vetando el acceso. A trabajos como los de Juan Manuel Escudero Baztán ${ }^{5}$, Evangelina Rodríguez ${ }^{6}$, Edith Marta Villarino ${ }^{7}$ o Paloma $\mathrm{Cuenca}^{8}$, que apoyan y defienden su faceta de entremesista o, al menos, elaboran un estado de la cuestión en el que se subraya la complejidad del asunto (cosa, ya de por sí, bastante intrincada), se oponen otros como la reciente Historia del teatro breve en España, dirigida por Javier Huerta Calvo9, en la que no se reserva ningún apartado a Lope, ni siquiera para exponer el entramado de interferencias y problemas de adjudicación en el que se hayan sumidas todas las obras que en algún momento se le prohijaron.

Sin duda, los hitos más concluyentes en este arduo camino los marcaron Joaquín de Entrambasaguas ${ }^{10} \mathrm{y}$, de manera conjunta, Fausta Antonucci y Stefano Arata $^{11}$, cuyos trabajos reconocieron la paternidad del dramaturgo para algo más de una quincena de loas. Sin embargo, y a pesar de todos los indicios propicios, la cautela sigue siendo la nota predominante en ellos ${ }^{12}$. Pareciera que lo que hubiera valido para resolver sospechas de atribución a favor de cualquier otro ingenio no

\footnotetext{
${ }^{4}$ Se trata de la conocida como Loa para una égloga cuyo íncipit era «Muy reverendo senado [...]». Para Antonucci y Arata la autoría de Lope en esta obra «parece segura». Véase Fausta Antonucci y Stefano Arata, La enjambre mala soy yo, el dulce panal de mi obra. Veintinueve loas inéditas de Lope de Vega y otros dramaturgos del siglo XVI, Madrid / Sevilla / Valencia, UNED / Universidad de Sevilla / Universidad de Valencia, 1995, pág. 24, n. 24.

${ }^{5}$ «El teatro breve de Lope de Vega», Ínsula, 658, Octubre de 2001, págs. 15-16.

${ }^{6}$ «Sobre los entremeses atribuidos a Lope de Vega», en C. Davis y A. Deyermond, eds., Golden Age Spanish Literature. Studies in Honour of John Varey by his Colleagues and Pupils, London, Westfield College, 1991, pág. 179-189.

${ }^{7}$ «El indiano, un entremés de Lope de Vega», Revista Signos, 25, 31-32, 1992, págs. 227-233.

8 «Estudio paleográfico de algunos autógrafos teatrales de Lope de Vega y edición del entremés de Melisendra (Res. 88)», Cuadernos para Investigación de la Literatura Hispánica, 24, 1999, págs. 149-194.

${ }^{9}$ Publicada en Madrid por la editorial Iberoamericana en el año 2008.

10 «Acerca de la atribución de una loa a Lope de Vega», en Estudios sobre Lope de Vega, Madrid, CSIC, 1958, vol. III, págs. 491-527.

${ }^{11}$ La enjambre mala soy yo..., cit.

${ }^{12}$ A este respecto, dirán Antonucci y Arata (ibíd., págs. 26-27): «Puesto que desde un punto de vista textual no hay razones de peso para poner en entredicho la atribución [a Lope] de los testimonios de Palacio, me parece correcto aceptar las indicaciones de los manuscritos; pero sin olvidar que, a falta de autógrafos, cualquier atribución de manuscritos teatrales es siempre una hipótesis de trabajo, y que para loas que han corrido por los escenarios, el concepto de paternidad tiene que ser forzosamente reducido aunque no eliminado».
} 
sirve cuando es el ajuste del corpus lopiano lo que se tiene entre manos. El peso del mito se deja sentir de forma inexorable exigiendo unas garantías legítimas desde el punto de vista científico, aunque tal vez un tanto radicales desde el de la sensatez filológica. Sería inviable elaborar una historia de la literatura sólo a partir de la existencia de manuscritos autógrafos. En otras palabras, creo que a estas alturas estamos en disposición de aceptar que Lope sí escribió piezas breves, ya que todos esos preludios dramáticos que acabamos de citar apuntan en esa dirección. No será la única evidencia como vamos a comprobar un poco más adelante.

Aunque esta vez sí desde planteamientos puramente especulativos, su propia personalidad invita ya a tomar en seria consideración la posibilidad de que en algún momento se aventurara a poner a prueba su ingenio escribiendo este tipo de obras. Otra cosa es que decidiera no adjudicárselas a sabiendas de que se trataba de un género que no aportaba a los dramaturgos el anhelado reconocimiento del sector más docto del auditorio. Nada tendría de extraño viniendo de un hombre tan preocupado por estas cuestiones. Como en tantas otras ocasiones, se encontraría ubicado en ese laberinto tan lopiano que se formaba al conjugar al hombre de teatro que dominaba su oficio y entendía la filosofía que lo sustentaba con el teórico que siente la necesidad de ganarse la aprobación de sus pares para ceñirse la corona dramática de su tiempo. El aplauso constante del público y su influjo sobre toda una cohorte de seguidores no le eran suficientes. Necesitaba lograr también el beneplácito de una serie de críticos de tinte conservador y continuista para sentir el triunfo como completo. Estamos ante el Lope contradictorio, aquel que queda retratado en su Arte nuevo de hacer comedias.

El Lope teorizador sabía de la importancia que tenían los intermedios dramáticos en la consideración global de la representación y en la suerte que corría la comedia a la que acompañaban. Testimonios de la época vinculan de forma directa la impresión que ésta dejaba en los espectadores con el potencial cómico de aquellos. En su Arte nuevo dedica al género unos famosos versos en los que se ocupa de la cuestión del decoro y, poco después, explica la evolución que en esos años había sufrido el conjunto de la representación:

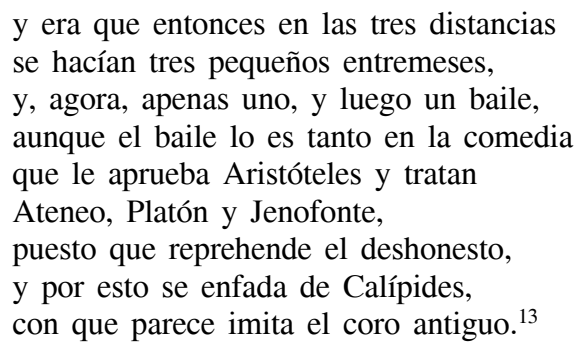

${ }^{13}$ Vv. 222-230. Cito por la edición de Juan Manuel Rozas, Madrid, SGEL, 1976, pág. 188. 
Hacia 1609, fecha de publicación del considerado como manifiesto fundacional del arte dramático moderno, los tres entremeses que se solían representar en la fiesta teatral se habían sustituido por uno solo y un baile. Nos encontramos también en un momento decisivo en el proceso de evolución y estilización del propio género breve, ya que, como señala Abraham Madroñal,

[...] por estas fechas está cambiando la estética de todo lo que afecta al entremés y al baile dramático, por cuanto la aparición en escena del más grande compositor de estas obritas, el toledano Luis Quiñones de Benavente hacia 1610, va a revolucionar la poética de la pieza breve porque impondrá el verso sobre la prosa y añadirá todo lo que tiene que ver con la música y la coreografía en un avance que consigue el sincretismo de géneros. Eso se aprecia especialmente en los bailes. ${ }^{14}$

Que Lope conocía a la perfección la enorme afición del público por presenciar bailes en las representaciones teatrales está fuera de toda duda. Su propensión a incluir o mencionar danzas en muchas de sus comedias así lo atestigua. De ello da buena cuenta José Castro Escudero ${ }^{15}$ en una serie de artículos en los que hace un repaso pormenorizado a los bailes y danzas que, directa o indirectamente, aparecen en su teatro.

El gusto popular por este tipo de piezas provoca una doble vertiente evolutiva en el género. Por una parte, las danzas cortesanas de raigambre medieval que se incluyen en las comedias se popularizan mediante la transformación de su solemnidad y suntuosidad consustanciales en sensualidad e insinuación a partir de unos movimientos que causan estupor en los moralistas y aclamación del público a partes iguales. Ante la imposibilidad de conseguir la efectiva prohibición de representar comedias, aquellos intentarán al menos que de ellas se extirpen los bailes, alguno de los cuales, como la chacona o la zarabanda, se juzgaban nacidas en el mismísimo infierno ${ }^{16}$.

14 «Un baile de Lope de Vega», Cuadernos del Lazarillo, 35, julio-diciembre de 2008, pág. 28.

${ }_{15}$ Para las referencias concretas remito al apartado bibliográfico final.

${ }^{16}$ El vehemente jesuita Padre Mariana, azote de los espectáculos públicos, definía la zarabanda como «[...] un baile y cantar tan lascivo de las palabras, tan feo de los meneos, que basta para pegar fuego aun a las personas muy honestas». Para colmo de su indignación, tenía por cierto que se había inventado en España: «¿Qué dirán cuando sepan (en otras partes)... que en España, donde está el imperio, el albergo de la religión y la justicia, se representan no sólo en secreto, sino en público, con extrema deshonestidad, con meneos y palabras a propósito los actos más torpes y sucios que pasan y hacen en los burdeles, representando abrazos y besos, y todo lo demás, con boca y brazos, lomos con todo el cuerpo, que sólo el referirlo causa vergüenza?» Por su parte, en el cervantino entremés de La cueva de Salamanca, el personaje del Barbero así lo considera: «PANCRACIO: Dígame, señor mío, pues los diablos lo saben todo, ¿dónde se inventaron todos estos bailes de las zarabandas, zambapalo y Dello me pesa, con el famoso del nuevo Escarramán? BARBERO: ¿Adónde? En el infierno; allí tuvieron su origen y principio». Las citas de Mariana las tomo de Cotarelo, Colección de entremeses..., cit., pág. CCLXX. La de Cervantes de Florencio Sevilla Arroyo y Antonio Rey Hazas, Miguel de Cervantes: Entremeses, Madrid, Alianza Editorial, 1998, pág. 168. 
La Reformación de comedias que decretó el Consejo de Castilla en 1615 trajo aparejada la prohibición de todos estos bailes lascivos cuyo incumplimiento supondría penas de multa y destierro. No era la primera vez ni sería la última en la que se promulgaba una ley de estas características aunque, como en tantas otras ocasiones, no tuvo ninguna consecuencia práctica en los escenarios. La afición hacia ellos será tal que en el concurso de licitación de los corrales de comedias madrileños que se llevó a cabo en 1629, uno de los pujadores tuvo la previsión de solicitar que «los bailes no se han de quitar honestamente, que es la salsa de las comedias y no valen nada sin ellos» ${ }^{17}$. La alabanza de los bailes antiguos como más preferibles y dignos de consideración que los nuevos (ya que «provocan sólo a gallardía y no a lascivia», como se alega en el memorial que presentó la villa de Madrid a Felipe II en 1598 solicitando el levantamiento de la prohibición de representar que se había adoptado poco tiempo antes ${ }^{18}$ ) unida a la queja por la laxitud con la que se aplica la disposición se convierte en un tópico al que Lope no será ajeno. En La Dorotea, publicada en 1632, señalaba que

[...] ya se van olvidando los instrumentos nobles, como las danzas antiguas, con estas acciones gesticulares y movimientos lascivos de las chaconas, en tanta ofensa de la virtud de la castidad y el decoroso silencio de las damas. ¡Ay de ti, alemana y pie de gibao, que tantos años estuvisteis honrando los saraos! $!^{19}$

Un año antes, en 1631, se había lamentado ante el rey y sus nobles, presentes en el estreno de La noche de san Juan, de que los bailes populares hubieran acabado con las danzas cortesanas. Como indica Madroñal ${ }^{20}$, dirigirá sin disimulo un ataque a Quiñones de Benavente, compañero suyo en esa fiesta palaciega, mencionando uno de los bailes que éste había puesto de moda:

Don Toribio: De los bailes, don Félix, vengo muerto.

Don Alonso: Tristes danzas de España, ya murieron.

Don Félix: Dios las perdone, gente honrada fueron.

17 Casiano Pellicer, Tratado histórico sobre el origen y progreso de la comedia y del histrionismo en España, 2 vols., Madrid, Imprenta de la Administración del Real Arbitrio de Beneficencias, 1804, I, pág. 132.

${ }^{18}$ Cito por Emilio Cotarelo, Controversias sobre la licitud del teatro, Madrid, Est. Tip. de la Rev. de Archivos, Bibl. y Museos, 1904, pág. 424.

${ }^{19}$ Cito a partir de Edwin S. Morby, ed., Lope de Vega. La Dorotea, Madrid, Castalia, 2001, pág. 133.

${ }^{20}$ «Un baile...», cit., pág. 28. La cita de los versos siguientes la tomo también de él. Señalo en cursiva aquellos en los que critica el baile de Benavente. 
Don Toribio: ¿Qué se hicieron gallardas y pavanas, pomposas como el nombre, y cortesanas?

Don Alonso: Se metieron a monjas.

Don Félix:

Cosa extraña

que ya todas las danzas en España se han reducido a zápiro y a zépiro a zípiro y a ñápiro.

Don Alonso: Por Dios que es gran donaire, no tenéis que decir.

Don Félix:

la gala y bizarría

Sí, pero el aire

con que el mayor señor danzar podía y los pies de gibaos, y alemanas y brandos en saraos; ¿por qué se han de dejar de todo punto?

Don Alonso: Hermano, porque todo el mundo junto se vuelve ya, como el vestido viejo: lo de atrás adelante.

Don Félix:

Mal consejo.

Don Alonso: La novedad, don Félix, siempre agrada, sea en razón o en sinrazón fundada. Mirad que aun la poesía no habla ya la lengua que solía.

El Lope renovador del arte escénico, el que había encontrado en el cambiante gusto del público la justificación perfecta para transgredir los preceptos de Aristóteles y sus comentaristas, cede la palabra al mito teatral que ya padece la amenaza del empuje con el que Calderón y los de su generación reclaman su hegemonía en la escena del Barroco. Él sabía muy bien que nada podía hacerse contra los tiempos cambiantes, por eso, en las últimas líneas del prólogo de $E l$ castigo sin venganza, ya al final de su vida, advierte que

[...] está escrita [su comedia] al estilo español, no por la antigüedad griega y severidad latina; huyendo de las sombras, nuncios y coros, porque el gusto puede mudar los preceptos, como el uso los trajes y el tiempo las costumbres. ${ }^{21}$

\footnotetext{
${ }^{21}$ Sobre el papel, en ocasiones contradictorio, que adopta Lope a la hora de asumir la responsabilidad de la revolución dramática que instaura la denominada comedia nueva y su empeño por
} 
Pronto el baile empieza a no tener cabida en el territorio de la comedia y debe refugiarse en los dominios del entremés, espacio regido por un código moral mucho más relajado y permisivo. Llegará a modificar incluso la estructura de estas obras pues sustituye al típico final caótico a golpe de matapecados. Estas codas adquirirán una entidad propia y reclamarán independencia a medida que el público se iba aficionando más a ellas. En 1616, según la opinión de Cotarelo $^{22}$, la escisión definitiva era ya un hecho y el baile pasa a configurar un subgénero breve diferente. El momento no es casual, ya que por aquel entonces se produce también el abandono de la prosa como vehículo comunicativo del entremés y la asunción del verso que estiliza y dinamiza el género ${ }^{23}$. Figura trascendental en todo este proceso, como ya sabemos, será Luis Quiñones de Benavente a quien su editor, Manuel Antonio de Vargas, le reconocía el mérito de haber creado un género nuevo que denominaba ditirámbico y en el que se unían «verso, música y trepudio».

Aunque el término baile se suele emplear de manera paradigmática, lo cierto es que bajo esta denominación se engloban una serie de variantes que tienen como elemento aglutinador a la música. Prueba de que ya resultaba confuso en la época debido a su polisemia es el hecho de que Quiñones de Benavente no denominara así a ninguno de los suyos, sino que sintió la necesidad de especificar su verdadera naturaleza llamándolos «entremeses cantados» ${ }^{24}$. El baile dramático, pues, requiere para su existencia de la presencia de una acción y de los principios activos de la misma: unos personajes que interactúen dialógicamente. Para Gaspar Merino Quijano, sus ingredientes adicionales serían la recitación, la música, el canto y el baile ${ }^{25}$. La definición más completa del subgénero la dio este investigador:

[...] cualquier intermedio teatral que tenga como motor o fin, como núcleo giratorio, el caminar hacia las mudanzas, bien sea introduciendo «bailes» o «danzas» (aristocráticas o populares) —con sus tonos y músicas correspon-

seguir apuntalando las bases en las que se asienta más allá del Arte nuevo de hacer comedias, puede verse Francisco Sáez Raposo, «El otro Arte nuevo: cuestiones de preceptismo dramático en las dedicatorias de las comedias de Lope de Vega», en G. Poggi y M. G. Profeti, ed., Norme per lo spettacolo. Norme per lo spettatore. Teoria e prassi del teatro intorno all" «Arte nuevo», Firenze, Alinea Editrice, 2011, págs. 173-183.

${ }^{22}$ Colección de entremeses, loas, bailes, jácaras y mojigangas desde fines del siglo XVI a mediados del XVIII, ed. de J. L. Suárez y A. Madroñal, Granada, Universidad de Granada, 2000, I, pág. CLXXXIII.

${ }^{23}$ Véase Eugenio Asensio, Itinerario del entremés, desde Lope de Rueda a Quiñones de Benavente, 2a ed., Madrid, Gredos, 1971, pág. 67-69.

${ }^{24}$ Curiosamente, el editor y recopilador de los mismos sí los rotuló con el nombre genérico de «bailes». Véase Cotarelo, Colección de entremeses..., cit., págs. CLXXXV y CLXXXVII.

${ }^{25}$ Los bailes dramáticos del siglo XVII, tesis doctoral, Universidad Complutense de Madrid, Madrid, 1980, vol. I, pág. 156. 
dientes - formando todo ello un argumento desarrollado por unos personajes, o bien introduciendo otros tonos y músicas creados expresamente, dando así vida juntamente con la letra argumental a una acción consistente, autónoma y dramática. ${ }^{26}$

Como ya sabemos, Lope aprovechó en sus comedias el potencial espectacular y dramatúrgico que música y danza le ofrecían, pero ¿escribió algún baile exento? No hace mucho, Madroñal ${ }^{27}$ respondió de manera afirmativa a esta pregunta en un artículo donde rescataba del olvido una pieza en la que ya se había fijado Entrambasaguas tres décadas antes ${ }^{28}$. Incluido en el denominado códice Daza, autógrafo de Lope, no cabe ninguna duda con respecto a su autoría. Se trata de una composición corta (74 versos) en la que es posible hallar características prototípicas del género, tales como la polimetría y el uso del denominado «lenguaje lúdico» ${ }^{29}$.

Uno de sus tres personajes de naturaleza entremesil (un sacristán, una moza tomajona y otro de nombre Perote) pretende componer un baile que recree la conocida fábula de Apolo y Dafne pero en la clave cómica del motivo de las mujeres que se afanan por desplumar a los hombres. Al carecer de título, Madroñal le dio el de Baile de Apolo y Dafne ${ }^{30}$. Asimismo, en el análisis que hace, encuentra puntos de contacto tanto con otras obras de Lope $^{31}$ como con algunas composiciones burlescas debidas a otros ingenios ${ }^{32}$, sobre todo a Pedro Calderón ${ }^{33}$. Madroñal incluso insinúa una posible relación entre el personaje con anhelos de comediógrafo del baile de Lope (el mencionado Perote) y el propio Calderón, ya que «[...] no se puede olvidar que Perantón es el nombre burlesco con el que se conocía a don Pedro por haber nacido el día de san Antón» ${ }^{34}$. La enemistad de los dos dramaturgos originada por el famoso asalto

26 Ibíd.

27 «Un baile...», cit.

${ }^{28}$ En Un códice de Lope de Vega autógrafo y desconocido, Madrid, CSIC, 1976.

${ }^{29}$ En éste, el elemento musical impone sus propias reglas de acentuación y creación léxica en las que el principio de la eufonía genera formas carentes de valor semántico cuyo objetivo era provocar la risa. Valga como ejemplo el estribillo de la canción: «Cúquili, áxili, trínguili, / cínguli, áxili, máxili».

$30 \ll$ Un baile...», cit., pág. 33 .

${ }^{31}$ Con un par de sonetos que aparecen en las Rimas de Burguillos (los titulados «A las fugas de Juan en viendo al poeta, con la fábula de Dafne» y «La necesidad en las mujeres se disculpa»), un baile incluido en la comedia El valor de las mujeres y, al menos en el título, con el Laurel de Apolo, publicado muy poco tiempo antes.

${ }^{32}$ A Salvador Jacinto Polo de Medina, Alonso Jerónimo de Salas Barbadillo y Jerónimo de Cáncer.

${ }^{33}$ Nos recuerda su zarzuela El laurel de Apolo, que fue estrenada en el Buen Retiro con tramoya debida a Cosme Lotti.

${ }^{34}$ Ibíd. 
de Calderón al convento de las Trinitarias donde vivía sor Marcela, la hija del Fénix, habría sido el detonante de esta mofa ${ }^{35}$.

Una cosa llama mi atención de forma especial: su fecha tan tardía de composición. Y es que es curioso que, en torno a $1632^{36}$, un Lope inmerso en pleno ciclo creativo de senectute alegue que desea escribir un baile según el uso moderno:

Perote: Un baile quiero yo hacer,
que también sé yo hacer bailes,
de buen gusto, si le diere,
de buen aire, si le hace.

Murrio: ¿Cómo le quieres hacer?

Perote: $\quad$ En este nuevo lenguaje, aunque un rato me rebele a la lengua de mis padres. ${ }^{37}$

¿Es ésta su primera tentativa en un género que llevaba en boga una década y media? No parece lógico. Sin embargo, en aquel entonces Quiñones de Benavente había dado al género su ajuste definitivo. A partir de la inauguración del Buen Retiro (ese mismo año) el entremesista toledano será un habitual en las representaciones cortesanas allí celebradas, en las que se dedicará, casi de manera exclusiva, a componer entremeses cantados. A ese «nuevo lenguaje» formulado por Benavente en sus bailes es a lo que se refiere Lope en sus versos.

Además de esta pieza de paternidad segura, existen también otros siete bailes que se han venido vinculando a la figura del Fénix. Sus títulos son: jAy, ay, ay! y el sotillo, El caballero de Olmedo, El duque de Humena, Don Jaime, La mesonerica, Pásate acá, compadre y un baile sin nombre cuyos dos primeros versos dicen «Reinando en Francia / Carlos el primero, [...]». En principio, el fundamento para sustentar dicha adscripción no es otro que el haber visto la luz en las partes séptima y octava de las comedias de Lope (ambas de 1617), con la excepción del primero de ellos, que apareció un año antes en Barcelona en la Flor de comedias de España de diferentes autores. Quinta parte, aunque, eso sí, ligado a su comedia El ejemplo de casadas y prueba de la paciencia. Como indica Madroñal, «no hay seguridad ninguna de que Lope compusiera estos bai-

\footnotetext{
35 Tras herir al hermano de Calderón, el actor Pedro de Villegas buscó sagrado en dicho convento no teniendo aquél reparo, en plena persecución, de saltar el muro e irrumpir violentamente en ese espacio de clausura.

${ }^{36}$ El propio Entrambasaguas, primer editor del texto, llegó a pensar que éste era «[...] el último texto dramático del Fénix de que se tiene noticia». Véase Entrambasaguas, Un códice de Lope de Vega..., cit., pág. 66.

${ }^{37}$ Cito por Madroñal, «Un baile...», cit., pág. 31. La cursiva es mía.
} 
les; pero tampoco evidencia en contra $»^{38}$. Sin embargo, la carencia absoluta de otros testimonios convierte la labor de adjudicación en un callejón sin salida.

Es el romance la combinación métrica medular en todos ellos. Sobre él se articula el ritmo introduciendo más o menos variaciones estróficas. Desde un punto de vista tipológico, las piezas pueden dividirse en dos grupos: los bailes propiamente dichos (El duque de Humena, Don Jaime, La mesonerica, El caballero de Olmedo y «Reinando en Francia [...]») y los bailes dramáticos (Pásate acá, compadre y el jAy, ay, ay! y el sotillo).

En los primeros no hay personajes y, por consiguiente, no existe la acción dramática, principio clave, como sabemos, en la distinción entre la saltación y la pieza con un mínimo componente dramático. La narración de un hecho a través de una letra cantada es su rasgo definitorio. En diferentes momentos de esa historia referida en forma de romance (o romancillo, como es el caso de $\mathrm{La}$ mesonerica) se van introduciendo una selección de danzas como «el caballero» (en El duque de Humena o El caballero de Olmedo), el «sarao» (en Don Jai$m e$ ), «el Rugero» (en «Reinando en Francia [...]»), etc.

Aunque en última instancia es el amor el asunto latente en todos ellos, en cuanto a su temática también se distinguen, con algunos matices, dos grandes ejes en torno a los que se formulan. El duque de Humena, Don Jaime y «Reinando en Francia [...]» evocan en sus letras un ambiente palaciego, aristocrático, como si estuvieran impregnadas de ese tono cortesano en el que florecieron las «danzas antiguas» que tan añoradas eran en estas primeras décadas del XVII. Las circunstancias genésicas del primero remiten al acuerdo matrimonial al que en 1611 llegaron las cortes española y francesa para estabilizar las relaciones políticas de ambos países, suavizadas tras el asesinato un año antes de Enrique IV en París, mediante los desposorios cruzados entre el futuro Felipe IV e Isabel de Borbón, por un lado, y Ana de Austria con Luis XIII de Francia, por otro. Fue el Duque de Mayenne, el de Humena en el baile, quien viajó a España para negociar los dobles matrimonios reales:

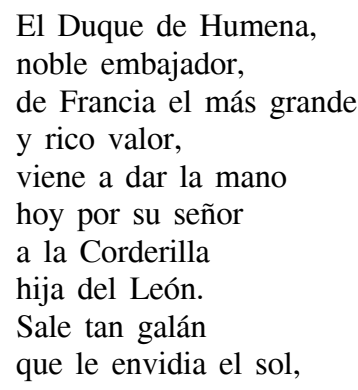

${ }^{38}$ Cit., pág. 31. 


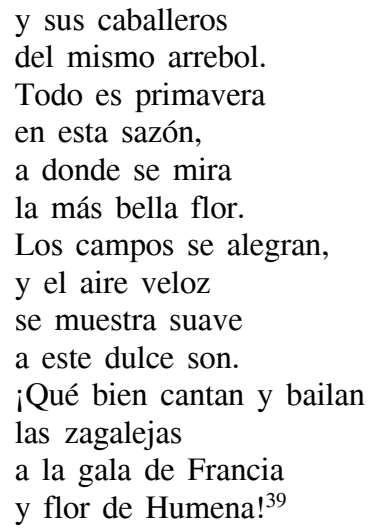

En la corte valenciana de Jaime I transcurre el baile homónimo y en la carolingia el que principia «Reinando en Francia [...]». Los dos tratan de fiestas: mientras que en el primero se destaca una suerte de certamen poético entablado en las celebraciones que mandó organizar el rey conquistador «después de estar vitorioso / de los moros de Valencia», el segundo recurre al imaginario creado por el famosísimo poema épico Orlando furioso (1532) de Ariosto para narrar el momento justo en el que Rugero (o Rogelio) baila con la dama Bradamante, hermana de Reinaldo, en la celebración de sus bodas en París. La danza es interrumpida por el anuncio de la llegada de las tropas sarracenas lideradas por Agramante, por lo que todos los caballeros, incluido el desposado, deben partir para hacerles frente. Podría decirse que estamos, en puridad, ante tres romances de tema novelesco, histórico-novelesco (o incluso lírico) e histórico-legendario de tema carolingio, respectivamente.

Los otros dos bailes englobados en este primer grupo (La mesonerica y $\mathrm{El}$ caballero de Olmedo) narran asuntos novelescos, pero esta vez protagonizados por personajes populares. En el primero, la moza de una posada se asoma a la ventana de la misma para, cual sirena, atraer con su canto a los viajeros que por allí pasen. Rendido a éste cae un extranjero

$$
\begin{aligned}
& {[\ldots] \text { justo de calzones }} \\
& \text { largo de garceta, } \\
& \text { ferreruelo abierto } \\
& \text { y gorra tudesca. } \\
& \text { Que trae Arliquín } \\
& \text { por mozo de espuelas, } \\
& \text { y es ropa de entrambos }
\end{aligned}
$$

${ }^{39}$ Cito por Cotarelo, Colección de entremeses..., cit., II, pág. 490. 
sola una maleta. ${ }^{40}$

La pieza, con ciertas pinceladas de ambientación marginal, termina con una danza referida en la narración pero que sería también materializada por tres actores en el escenario:

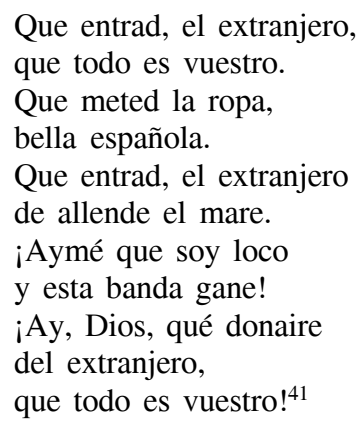

Del celebérrimo tema del caballero de Olmedo da cuenta el segundo. Con la excepción de los ochos versos finales, en los que se aprovecha el asunto para traer a colación el baile de «el caballero», la pieza reúne las características de un auténtico romance novelesco. De todos los bailes relacionados con Lope, sólo éste se publicó en su día atribuido de forma expresa a su pluma ${ }^{42}$. Cotarelo indicaba que el comediógrafo es el autor de la comedia homónima, «[...] pero no consta que lo sea de este baile» ${ }^{43}$, y ésa ha sido la opinión comúnmente aceptada. El asesinato real acaecido en las inmediaciones de la vallisoletana villa de Olmedo en 1521 debió generar un romance que, con todas las licencias novelescas que queramos, fue el germen de la leyenda. Francisco Rico considera que con el asentamiento de la corte en Valladolid entre 1601 y 1606 se despertó la curiosidad «por las cosas de la capital y de la región, volviéndolas familiares a visitantes y correveidiles» ${ }^{44}$. De este modo, se recuperó un poema cantando que llevaría décadas relegado a las zonas próximas al lugar del crimen. Pronto se convirtió en baile para ser ejecutado en intermedios teatrales adoptando toda una serie de motivos tomados del romancero morisco, sobre todo del ciclo de $\mathrm{Gazul}^{45}$. Una de las derivaciones de este baile primigenio se-

40 Cito por Cotarelo, Colección de entremeses..., cit., II, pág. 492.

${ }^{41}$ Aunque cito por Cotarelo (ibíd., II, pág. 493), corrijo un par de lecturas erróneas que aparecen en él.

42 «Baile famoso del Caballero de Olmedo, compuesto por Lope de Vega».

${ }^{43}$ Ibíd, II, pág. 491, n. 1. Para Rico, Lope, «[...] desde luego, no tuvo nada que ver ni con la impresión del volumen ni menos con la redacción de la obrilla (83 versos) que se le cuelga». Así en Francisco Rico, ed., Lope de Vega, El caballero de Olmedo, Madrid, Cátedra, 1990, pág. 48.

44 Véase Rico, ibíd.., pág. 45. 
ría el nuestro que, a su vez, evoluciona en un par de versiones manuscritas incluidas en el Cancionero de 1615 y en una miscelánea perteneciente a la Hispanic Society of America ${ }^{46}$. Para Rico, «todas las recreaciones poéticas de la historia del Caballero hechas en el siglo XVII [...] están en deuda importante con el baile teatral [...]» ${ }^{47}$. Entre ellas, incluye la obra maestra del Fénix.

Parecería que el baile se incorporó, pues, a la Parte VII de Lope por asociación con su comedia. Todo encajaría a la perfección si no fuera porque esta última fue escrita en torno a 1620, es decir, con posterioridad a aquél. La respuesta al porqué se produciría en el público esa asociación entre el Fénix y el baile hay que buscarla en otros lugares. Por ejemplo, en la comedia El santo negro Rosambuco de la ciudad de Palermo y en los autos de El pan y el palo y el de Los cantares. Aunque de este último no tenemos datos precisos, sabemos que los otros dos debieron preceder al baile, ya que la primera se considera anterior a 1607 y el segundo se representó en la corte hacia 1612. En los tres aparece incluido, con curiosas variantes a lo paródico y a lo divino, el cantarcillo popular que sería origen de nuestra pieza y también de la comedia. ¿Se hizo tan popular que terminó adoptando identidad propia en forma de baile exento para ser representado en el entreacto de la función? ¿Fue este éxito lo que motivó a Lope a convertir el asunto en comedia? Sea como fuere, estas versiones implican un conocimiento previo y generalizado de un modelo emulado, ya que por sí solas no sirven para salvar la distancia que las separa del baile. Ésta puede quedar cubierta por El caballero de Olmedo, anónimo ${ }^{48}$ «melodrama» (en palabras de Rico $^{49}$ ) en cuyo manuscrito (conservado en la Biblioteca Nacional de España) aparece consignada la fecha de 1606. Shergold elucubra sobre la posibilidad de que Lope presenciara la representación de esta obra en Madrid a finales del año siguiente (obtuvo su licencia de representación en ese momento) o en $1608^{50}$. Más seguro parece que lo hiciera el autor del baile, pues deta-

\footnotetext{
45 Ibíd., pág. 47: «la rivalidad y las amenazas por celos; el galán que se lleva los ojos de las mujeres («a las ventanas», en los balcones), al pasear la plaza, triunfar en los toros y en los juegos de cañas, en un ambiente con rica decoración de cabalgaduras, armas, vestidos; «las cañas» que «se vuelven lanzas», y Gazul que atraviesa con una, «a la mitad de la noche», el cuerpo del pretendiente que ha conseguido a la dama; la maldición de Zaida, «esposa y viuda en un punto», para que a Gazul —en perpetuo ir y venir entre (Medina) Sidonia y Jerez-, de vuelta a su lugar, «en medio del camino», se le hiele la sangre al salirle al encuentro otro rival, que ojalá lo deje «cautivo... o muerto», etc.».

46 Ibíd., pág. 49.

47 Ibíd., págs. 51-52.

${ }^{48}$ Se ha atribuido, sin mucho fundamento, al actor Cristóbal de Morales.

49 Ibíd. pág. 56.

${ }^{50}$ Véase Norman D. Shergold, «Lope de Vega and the Other Caballero de Olmedo», en R. O. Jones, coord., Studies in Spanish Literature of the Golden Age presented to E. M. Wilson, London, Tamesis, 1973, pág. 280.
} 
lles como la total coincidencia del nombre de la dama (doña Elvira Pacheco, diferente al de doña Inés que tiene en la obra de Lope) sólo se explican por el conocimiento del texto que, por cierto, no se publicó impreso hasta después de $1626^{51}$.

Otro caso muy significativo lo constituye el baile «Reinando en Francia [...]». De tema ariostesco, como ya sabemos, Calderón lo incluye de manera casi literal en la versión de dos jornadas que preparó de El jardín de Falerina, tal vez representada, en opinión de Cruickshank, el 25 de junio de 1649 en el Palacio de la Zarzuela ${ }^{52}$. Refundición de la comedia homónima que escribió en colaboración con Rojas Zorrilla y Coello, y considerada como uno de sus primeros experimentos con el género de la zarzuela, sobre el texto cantado intercala, en un momento de la acción, un diálogo hablado ${ }^{53}$ en el que van interactuando diversos personajes entre los que destacan Rugero y Bradamante. La ambientación cortesana se ve completada por la combinación de danza, música, canto y diálogo que crea un pasaje de una gran complejidad estructural ya que, además, todo transcurre a un nivel metateatral en el que los personajes de Lisidante y Marfisa presencian esta escena de la corte francesa de Carlomagno gracias a la magia de Merlín. Con más variantes lo reproduce en El castillo de Lindabridis y El pintor de su deshonra.

Como es bien sabido, Calderón fue muy propenso a la reescritura como forma de creación dramática ${ }^{54}$. Además, en la década de 1630 el propio Lope se quejaba de que los jóvenes dramaturgos, liderados precisamente por Calderón, no tenían reparos en escribir sus obras e instaurar un estilo a base de saquear las suyas. A pesar de ello, creo que hay que descartar la posibilidad de que se aventurase a incluir en una de sus creaciones (representada en palacio) un baile compuesto por el Fénix sin ni siquiera realizar algunos mínimos retoques que lo enmascarasen. Pero es que además de Calderón, Luis Vélez de Guevara y Salas Barbadillo se sirvieron también de estos versos. No serán los únicos, pues su huella se encuentra en varios entremeses, una loa y otras composiciones (teatrales y poéticas) que los recogen en tono paródico o arreglados a lo divino. Incluso Cervantes, en La elección de los alcaldes de Daganzo, los recuerda ${ }^{55}$. En

${ }^{51}$ Véase Rico, ed. cit., pág. 56, n. 36.

${ }^{52}$ Según él, pudo ser esa «comedia cantada» que se representó en aquel sitio de recreo en esa fecha. Véase Don W. Cruickshank, Don Pedro Calderón, Cambridge, Cambridge University Press, 2009, págs. 173-174.

${ }^{53} \mathrm{La}$ acotación dice «Los instrumentos suenan siempre, aunque se represente».

${ }^{54}$ Marc Vitse lo definió, de hecho, como el dramaturgo áureo de la reescritura por antonomasia. Véase «Presentación», en M. Vitse, coord., Actas del Seminario "Siglo de Oro y Reescritura. I: Teatro», Criticón, 72, 1998, pág. 6.

${ }^{55}$ Véase Máxime Chevalier, Los temas ariostescos en el romancero y la poesía española del Siglo de Oro, Madrid, Castalia, 1968, págs. 227-233. 
esta cadena de influencias existe un eslabón perdido que podría aportar algo de luz en el asunto. La comedia titulada, precisamente, El jardín de Falerina, que Lope menciona como suya en el listado de El peregrino en su patria de 1604 y que se encuentra desaparecida. ¿Formaría parte de su trama un baile que luego seguiría pasos similares a los trazados para el de El caballero de Olmedo?

Traducido, imitado, adaptado y parafraseado con entusiasmo durante todo el Siglo de Oro, los personajes, situaciones y escenas del Orlando furioso se adecuaron sin ninguna dificultad al gusto del momento. Máxime Chevalier halló más de un centenar de temas ariostescos que se incorporaron al romancero y otras formas poéticas de esta época. De ellos, casi una treintena se centran en la relación entre Rugero y Bradamante, lo que constituye un verdadero ciclo en sí mismo. Me decanto, pues, por ubicar el foco irradiador del reiterado motivo en un romance de origen culto que se incorporaría a ese acervo que pertenecía al grupo y no al individuo, esa especie de arcón comunitario del que el artista podía tomar asuntos para conocerlos, estudiarlos y superarlos desde un punto de vista estético, pues el reto consistía en conseguir mayor perfección, no mayor originalidad.

Como ya dije, son dos los bailes que conforman la otra categoría en la que se puede dividir este corpus de piezas que estamos repasando. Se trata de Pásate acá, compadre y el ;Ay, ay, ay! y el sotillo, obras que cuentan con personajes y que, a pesar de la mayor o menor fortuna con la que desarrollan sus argumentos, constituyen auténticos bailes dramáticos. Y hablo de diversa fortuna porque en el caso del primero esa inclusión de personajes supone una evolución con respecto al grupo anterior pero genera sólo un conato de argumento. La parte cantada se ejecuta a dos voces de forma alterna por medio de un diálogo, aunque éste no pase de ser una mera petición de bailes (el polvillo, la catalineta, etc.) de una mujer a un músico. Todo ello ubicado de manera evocadora en el ambiente costumbrista de una suerte de jornada de descanso y esparcimiento a las orillas del Manzanares (en la línea de otros bailes como el de El sotillo de Manzanares), en la que ya desde la introducción contextualizadora se expone el deseo de todos por entregarse con denuedo a bailar. Un único destello asoma en el diálogo para propiciar el intento de atribuir su paternidad a Lope: el afán de la mujer por incluir, entre tanto baile, uno antiguo, a lo que el músico responde con la reticencia propia del innovador que considera que en el cambio radica la mejora:

Mujer: $\quad$ ¿No haremos un baile antiguo entre tantas novedades?

Músico: $\quad$ Si es bueno llamalde nuevo, que todo lo nuevo aplace. ${ }^{56}$

${ }^{56}$ Cito a partir de Cotarelo, Colección de entremeses..., cit., II, pág. 493. 
Cualquiera de los dos Lopes, el decidido renovador (léase el fragmento en sentido recto) y el nostálgico de las danzas de antaño (hágase en tono irónico) estaría en disposición de firmar una declaración como la del músico.

El ¡Ay, ay, ay! y el sotillo es el más elaborado de los bailes hasta aquí vistos y cuenta con un decidido componente dramático. La abundancia de didascalias en las que se puntualiza sobre la ejecución de los bailes y los ademanes interpretativos así lo atestigua. En cuanto a los usos métricos es además el más rico, pues presenta una mayor variedad estrófica (romance, seguidilla, redondilla y pareados) en consonancia con el patrón implantado por Quiñones de Benavente, en cuyas piezas era habitual que empleara entre tres y cinco modalidades diferentes ${ }^{57}$. Una vez más, nos encontramos en las riberas del Manzanares, donde dos fregonas reconocen las voces de sendos lacayos que, en compañía de unos músicos, les dedican algunos requiebros en forma de canción. El ambiente, otra vez, es costumbrista, de bajo mundo, incluso con alguna pincelada de picaresca.

La reunión de todos los personajes propiciará la ejecución de diversos bailes, entre ellos, como no, el del jAy, ay, ay!, que sirve de colofón a la pieza:

\section{(Cantan y bailan)}

$\begin{array}{ll}\text { Músicos: } & \text { ¡Ay, ay, ay } \\ & \text { estopilla de Cambray! } \\ & \text { ¡Ay, ay, ay! que el ¡ay, ay, } \\ & \text { que hasta el alma se me ha } \\ & \text { Quien el ¡ay, ay, ay! no bail } \\ & \text { el gusto tiene estragado. } \\ & \text { ¡Ay, ay, ay! } \\ \text { Fregona } 1^{\text {aa }} \text { : } & \text { En un pocito de celos, } \\ & \text { ¡ay, ay!, estoy metida, } \\ & \text { que si el amor no me saca, } \\ & \text { ¡ay, ay, ay!, yo soy perdida } \\ & \text { ¡Ay, ay, ay! } \\ & \text { Todos dicen ¡ay, ay! } \\ & \text { ¡Ay, ay! con todos diga. } \\ & \text { ¡Mal haya quien no dijere } \\ & \text { ay, ay, ay, como yo digo! } \\ & \text { ¡Ay, ay, ay! }{ }^{58}\end{array}$

${ }^{57}$ Véase, Javier Huerta, Antología del teatro breve español del siglo XVII, Madrid, Biblioteca Nueva, 1999, pág. 54.

${ }^{58}$ Cito a partir de Cotarelo, Colección de entremeses..., cit., II, pág. 478. 
Para Cotarelo, estaríamos por consiguiente ante la pieza que daría fama a este baile ${ }^{59}$. Su vinculación con Lope proviene del lugar que ocupa en un volumen (la Flor de comedias de España de diferentes autores. Quinta parte ${ }^{60}$ ) que transmite una intención de presentar las comedias allí recogidas en una suerte de simplificado remedo de fiesta teatral. Es decir, se imprime tras la loa que comienza «Mi tío el cura escribió [...]», englobada entre las del Fénix ${ }^{61}$, y la primera jornada de la comedia El ejemplo de casadas y prueba de la paciencia. La fecha de composición de ésta, entre 1599-1603, y las características del baile descartan la posibilidad de que Lope lo escribiera para ser representado junto a ella, es decir, se aunarían por motivos editoriales y no con el interés testimonial de reproducir una fiesta teatral concreta. Aunque todas las comedias que aparecen en este volumen se atribuyen de forma correcta a sus respectivos autores, no ocurre lo mismo con las piezas breves.

Por otro lado, de todos los bailes analizados, es el único que recurre, entre otras, a las mismas formas métricas (el romance y la seguidilla) que el denominado Baile de Apolo y Dafne. Es por todo ello el candidato que reúne los mejores requisitos para ser adjudicado al genio creador de Lope.

En conclusión, a pesar de las reticencias que existen al respecto, hoy podemos confirmar la faceta de entremesista (en el sentido genérico del término) de Lope de Vega. Un puñado de loas y, al menos, un baile dramático así lo atestiguan. A esta lista es muy posible que haya que añadirse otros títulos, entre ellos, el de alguno de los bailes dramáticos que desde siempre se le han atribuido. Que el dramaturgo decidiera comenzar su andadura por la senda de este subgénero en los años finales de su vida parece poco convincente. Aunque sin argumentos plenamente concluyentes, creo que estamos en disposición de descartar de esta nómina a aquellas piezas que aún no reúnen los requisitos necesarios para ser considerados bailes dramáticos estrictamente hablando. ¿Por qué querría Lope escribir este tipo de piezas? No podemos contestar a esta pregunta, pero tampoco parece razonable pensar que se aviniera a otorgar un estatus de privilegio a unas composiciones que podían subsistir y obtener fama en el seno de una comedia. El reto que esto suponía para alguien que monopolizaba el negocio teatral del momento y que, además, declaraba sin ambages «que también sé yo hacer bailes» en el Baile de Apolo y Dafne era nulo. Más aún cuando son piezas que ni siquiera encajan con los preceptos con los que estaba revolucionando el género en ese momento Luis Quiñones de Benavente, «metrópoli de bailes», según la definición que de él dio Hurtado de Mendoza. Que

\footnotetext{
59 Ibíd., I, pág. CLXXXIV.

${ }^{60}$ Publicada en Barcelona, por Sebastián de Cormellas, en 1616.

${ }^{61}$ Cotarelo, sin embargo, la considera anónima. Véase su Colección de entremeses..., cit., II, págs. 416-417.
} 
Lope se adentrara en los dominios de un género considerado menor con respecto a la comedia de la que dependía (y en la que él marcaba tendencia) para escribir bailes a contracorriente de la fórmula que había rendido ya el gusto del público es impensable. Del mismo modo, que accediera a que sus bailes (y piezas breves en general) se representaran a esas alturas de su trayectoria en los intermedios de comedias ajenas se me antoja también bastante improbable. Aparte del prohijamiento forzoso de piezas con vistas a la obtención de un beneficio teatral o editorial (algo contra lo que tantas veces protestó, de manera acentuada, en estos primeros años del siglo XVII), nada tendría de extraño que algún baile o cancioncilla incluida en sus comedias se popularizase de tal manera que terminase convertido en una pieza independiente y con autonomía propia. Tampoco sería raro lo contrario, es decir, que explotase en beneficio propio el éxito de una pieza adjudicada a él de manera arbitraria para convertir su asunto en núcleo de una suya. Esto es lo que debió suceder, por ejemplo, con el Baile famoso del Caballero de Olmedo.

Mayores dudas suscitan el Pásate acá, compadre y el ;Ay, ay, ay y el sotillo! Ese comentario (capcioso o no) sobre la equiparación entre la novedad y la calidad que pronuncia el músico en el primero parece el único nexo objetivo, aunque frágil, que podría sustentar la autoría de un baile que tiene más de lírico y folclórico que de dramático. El motivo se terminó convirtiendo en tópico, por lo que el espíritu de Lope que pudiéramos intuir en la declaración bien podría haberse difuminado e incorporado a un sentir más comunitario. Es el último, sin duda, el que más trazas tiene de ser aceptado para formar parte de la exigua nómina de piezas breves del Fénix. Su complejidad, su similitud con el único baile verdaderamente suyo y, a su vez, con los usos impuestos por Quiñones de Benavente para el género, la decidida naturaleza teatral que transpira la primera parte de la pieza (la correspondiente al diálogo entre las dos fregonas), así como el importante número de acotaciones que aportan información sobre la manera de cantar y bailar, pero también de actuar, apuntan en ese sentido. Sólo nos queda esperar a que el azar pueda, quizás, esclarecer estas hipótesis y otras que vayan surgiendo para así resolver de una vez por todas el enigma entremesil del Fénix.

\section{BIBLIOGRAFÍA}

Antonucci, Fausta y Arata, Stefano, La enjambre mala soy yo, el dulce panal de mi obra. Veintinueve loas inéditas de Lope de Vega y otros dramaturgos del siglo XVI, Madrid / Sevilla / Valencia, UNED / Universidad de Sevilla / Universidad de Valencia, 1995.

Asensio, Eugenio, Itinerario del entremés, desde Lope de Rueda a Quiñones de Benavente, $2^{\mathrm{a}}$ ed., Madrid, Gredos, 1971.

Castro Escudero, José, «Bailes y danzas en el teatro de Lope de Vega», en Les Langues Néo- 
Latines, 150, 1959, págs. 66-74; 156, 1968; 185, 1968, págs. 25-39; 188-189, 1969, págs. 1932; 202, 1972, págs. 20-33; 225, 1978, págs. 7-32.

Chevalier, Máxime, Los temas ariostescos en el romancero y la poesía española del Siglo de Oro, Madrid, Castalia, 1968.

Cotarelo, Emilio, Colección de entremeses, loas, bailes, jácaras y mojigangas desde fines del siglo XVI a mediados del XVIII, en J. L. Suárez y A. Madroñal, ed., 2 vols., Granada, Universidad de Granada, 2000.

Cotarelo, Emilio, Controversias sobre la licitud del teatro, Madrid, Est. Tip. de la Rev. de Archivos, Bibl. y Museos, 1904.

Cruickshank, Don W., Don Pedro Calderón, Cambridge, Cambridge University Press, 2009.

Cuenca Muñoz, Paloma, «Estudio paleográfico de algunos autógrafos teatrales de Lope de Vega y edición del entremés de Melisendra (Res. 88)», Cuadernos para Investigación de la Literatura Hispánica, 24, 1999, págs. 149-194.

Entrambasaguas, Joaquín, «Acerca de la atribución de una loa a Lope de Vega», en J. de Entrambasaguas, Estudios sobre Lope de Vega, Madrid, CSIC, 1958, vol. III, págs. 491-527.

Entrambasaguas, Joaquín, Un códice de Lope de Vega autógrafo y desconocido, Madrid, CSIC, 1976.

Escudero Baztán, Juan Manuel, «El teatro breve de Lope de Vega», Ínsula, 658, octubre de 2001, págs. 15-16.

Huerta Calvo, Javier, Antología del teatro breve español del siglo XVII, Madrid, Biblioteca Nueva, 1999.

Huerta Calvo, Javier, dir., Historia del teatro breve en España, Madrid, Iberoamericana, 2008.

Jauralde Pou, Pablo, dir., Diccionario filológico de literatura española (Siglo XVII), 2 vols., Madrid, Castalia, 2010.

Lobato, María Luisa, Pedro Calderón de la Barca. Teatro cómico breve, Kassel, Reichenberger, 1989.

Madroñal, Abraham, «Un baile de Lope de Vega», Cuadernos del Lazarillo, 35, julio-diciembre de 2008, págs. 27-34.

Merino Quijano, Gaspar, Los bailes dramáticos del siglo XVII, tesis doctoral, 2 vols., Universidad Complutense de Madrid, Madrid, 1980.

Morby, Edwin S., ed., Lope de Vega. La Dorotea, Madrid, Castalia, 2001.

Morley, S. Griswold y Bruerton, Courtney, Cronología de las comedias de Lope de Vega, Madrid, Gredos, 1968.

Pellicer, Casiano, Tratado histórico sobre el origen y progreso de la comedia y del histrionismo en España, 2 vols., Madrid, Imprenta de la Administración del Real Arbitrio de Beneficencia, 1804.

Rico, Francisco, ed., Lope de Vega, El caballero de Olmedo, Madrid, Cátedra, 1990.

Rodríguez Cuadros, Evangelina, «Sobre los entremeses atribuidos a Lope de Vega», en C. Davis y A. Deyermond, eds., Golden Age Spanish Literature. Studies in Honour of John Varey by his Colleagues and Pupils, London, Westfield College, 1991, págs. 179-189.

Rodríguez Cuadros, Evangelina y Tordera, Antoni, Pedro Calderón de la Barca. Entremeses, jácaras y mojigangas, Madrid, Castalia, 1990.

Rodríguez Cuadros, Evangelina y Tordera, Antoni, Calderón y la obra corta dramática del siglo XVII, London, Tamesis Books, 1983.

Rozas, Juan Manuel, Significado y doctrina del «Arte nuevo» de Lope de Vega, Madrid, SGEL, 1976.

Sáez Raposo, Francisco, «El otro Arte nuevo: cuestiones de preceptismo dramático en las dedicatorias de las comedias de Lope de Vega», en G. Poggi y M. Grazia Profeti, ed., Norme per lo spettacolo. Norme per lo spettatore. Teoria e prassi del teatro intorno all" "Arte nuevo», Firenze, Alinea Editrice, 2011, págs. 173-183. 
Sáez Raposo, Francisco, «Félix Lope de Vega Carpio. Teatro menor», en P. Jauralde Pou, dir., Diccionario filológico de literatura española (Siglo XVII), Madrid, Castalia, 2010, vol. I, págs. 863-886.

Sevilla Arroyo, Florencio y Rey Hazas, Antonio, Miguel de Cervantes: Entremeses, Madrid, Alianza Editorial, 1998.

Shergold, Norman D., «Lope de Vega and the Other Caballero de Olmedo», en R. O. Jones, coord., Studies in Spanish Literature of the Golden Age presented to E. M. Wilson, London, Tamesis, 1973, págs. 267-282.

Villarino, Edith Marta, «El indiano, un entremés de Lope de Vega», Revista Signos, 25, 31-32, 1992, págs. 227-233.

Vitse, Marc, «Presentación», en M. Vitse, coord., Actas del Seminario «Siglo de Oro y Reescritura. I: Teatro», Criticón, 72, 1998, págs. 5-8.

Fecha de recepción: 13 de diciembre de 2010

Fecha de aceptación: 14 de junio de 2011 